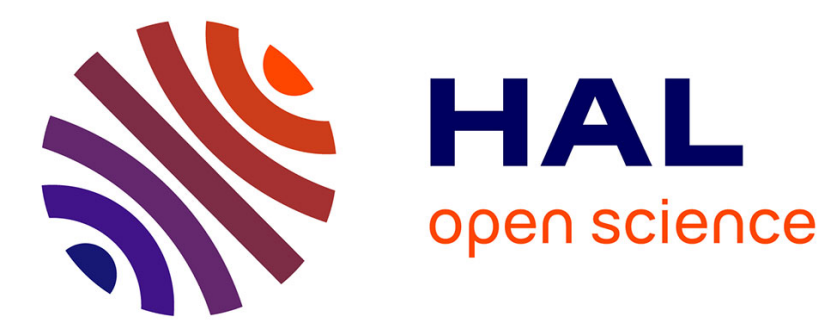

\title{
Principles for Controlling the Electronic Quality of High-Rate Deposited a-Si:H Films
}

\author{
G. Suchaneck, T. Blum, S. Röhlecke, A. Kottwitz
}

\section{To cite this version:}

G. Suchaneck, T. Blum, S. Röhlecke, A. Kottwitz. Principles for Controlling the Electronic Quality of High-Rate Deposited a-Si:H Films. Journal de Physique IV Proceedings, 1995, 05 (C5), pp.C5-655C5-661. 10.1051/jphyscol:1995578 . jpa-00253940

\section{HAL Id: jpa-00253940 https://hal.science/jpa-00253940}

Submitted on 1 Jan 1995

HAL is a multi-disciplinary open access archive for the deposit and dissemination of scientific research documents, whether they are published or not. The documents may come from teaching and research institutions in France or abroad, or from public or private research centers.
L'archive ouverte pluridisciplinaire HAL, est destinée au dépôt et à la diffusion de documents scientifiques de niveau recherche, publiés ou non, émanant des établissements d'enseignement et de recherche français ou étrangers, des laboratoires publics ou privés. 


\title{
Principles for Controlling the Electronic Quality of High-Rate Deposited a-Si:H Films
}

\author{
G. Suchaneck(1), T. Blum, S. Röhlecke and A. Kottwitz \\ Dresden University of Technology, Institute of Semiconductor Technology and Microsystems, \\ Mommsenstr. 13, 01062 Dresden, Germany
}

\begin{abstract}
By altering the plasma generation frequency, applying a magnetic field, changing the plasma regime from the low voltage $\alpha$-regime where the dominant electron-energy gain mechanism is related to the sheath expansion, to the high voltage $\gamma$-regime where the discharge is maintained by secondary electrons emitted by the electrodes under ion bombardment, or generating a highly excited low-pressure plasma in a helicon-type source the influence of the particle and energy flux to the substrate on the a-Si:H film electronic properties was investigated. Deposition rate simulation was performed regarding a radical source located at the sheath/plasma boundary. Radical losses due to diffusion and reactive collisions with gas molecules were taken into account.
\end{abstract}

\section{INTRODUCTION}

Recently improved in stability against illumination, low hydrogen containing a-Si:H films with a relaxed Sibond network were deposited by hot-wire-assisted CVD [1,2], low r.f. power remote PECVD [3], higher substrate temperature $\left(300-400^{\circ} \mathrm{C}\right) \mathrm{PECVD}[4,5]$ and post-deposition "chemical annealing" using atomic hydrogen, $\mathrm{Ar}^{*}$ and $\mathrm{He}^{*}[6,7]$. It was assumed that the surface mobility of growth precursors determines material quality.

This paper deals with the influence of the particle and energy flux to the substrate on the a-Si:H film electronic properties.

\section{EXPERIMENTAL}

High rate film deposition was performed by: 1 - rotating (2-pole and 4-pole) magnetic field enhanced discharges at 1.2 and $13.56 \mathrm{MHz}$ [8], 2 - multipole magnetic field enhanced discharges at 3.6, 13.56 and 27.12 MHz [9], 3 - very high frequency (20-100 MHz) discharges [8], 4 - $\gamma$-regime discharges at 13.56 $\mathrm{MHz}$ [10], 5 - VHF helicon-type discharges. The configuration of the helicon-source has been previously described in detail [11]. A high helium dilution was used in the latter case, so that silane dissociation is expected to be mainly due to excitation transfer from $\mathrm{He}^{*}$.

Improved in stability, high rate $(3$ to $8 \mathrm{~nm} / \mathrm{s})$ a-Si:H films with reduced hydrogen content and without detectable hydrogen on internal surfaces, with a TAUC-gap of 1.67-1.72 eV (fig. 1) indicating an improved structural order $[1,12]$, a photo- to dark-conductivity ratio of more than $10^{4}$, a density of silicon dangling bonds determined by the constant photocurrent method [8] of about $10^{16} \mathrm{~cm}^{-3}$ and a light-soaked dangling bond density of 5 to $8 \cdot 10^{16} \mathrm{~cm}^{-3}$ were deposited at a substrate heater temperature of $250^{\circ} \mathrm{C}$ adjusting a well defined ion flux by means of the variation of the strength of the rotating multipole magnetic field or the variation of the frequency. No microcrystalline phase formation was found by RAMAN-scattering in these films, although small changes in deposition conditions led to the formation of $\mu \mathrm{c}$-films with both reduced TAUC-gap and photo- to dark conductivity ratio.

A decrease of sheath thickness and a corresponding increase of the deposition rate is observed both when a rotating magnetic field is applied or when the plasma generation frequency is increased. However, differences in ion current to the electrode and ion energy distribution occur (fig. 2).

(1) Correspondence to: Technische Universität Dresden, Institut für Halbleiter- und Mikrosystemtechnik, Mommsenstr. 13, 01062 Dresden, Germany 


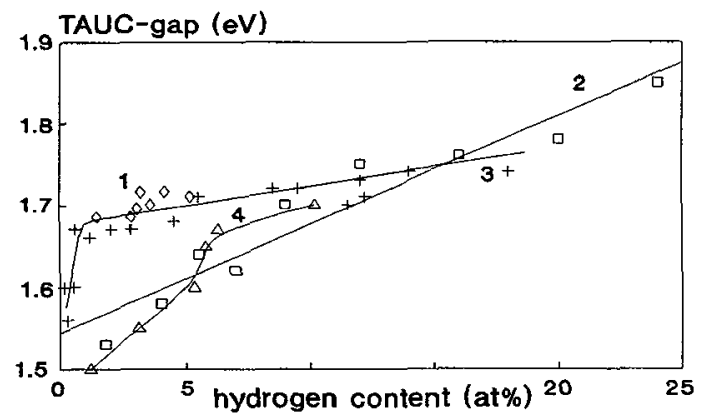

Figure 1: Bandgap versus hydrogen content; 1 - this work, 2 - PECVD [1], 3 -hot-wire-assisted CVD [1], 4 - „,chemical“ annealing [6]

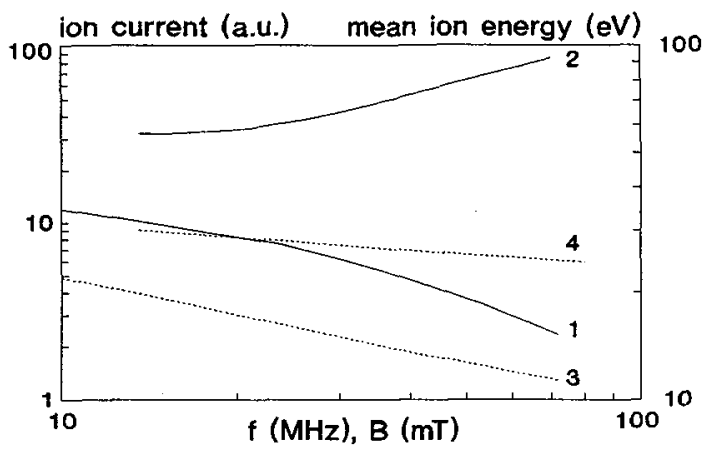

Figure 2: Ion current to the electrodes $(1,2)$ and mean ion energy $(3,4)$ in dependence on magnetic field (1,3 - experiment) $[8]$ and frequency $(2,4$ - calculation using PLASMM)

\section{DEPOSITION RATE SIMULATION}

Plasma-chemical-vapor-deposition is characterised by the decomposition of the source-gas materials by electron impact dissociation, creating neutral and charged radicals which are much different from the fragments of thermal CVD. The main secondary processes are gas phase chemical reactions of the fragments and their diffusive transport to the substrate surface. Neutral species are the most dominant ones, the fraction of charged species contributing to film deposition is low.

Discharge simulation was performed using the PC-code PLASIM [13]. This code estimates the mean energy $\left\langle\mathrm{E}_{\mathrm{c}}\right\rangle$ of bulk electrons by solving the equation:

$$
\mathrm{n} \cdot \Lambda=\sqrt{\frac{2 \cdot \mu_{\mathrm{i}} \cdot\left\langle\mathrm{E}_{\mathrm{c}}\right\rangle}{3 \cdot \mu_{\mathrm{e}} \cdot \mathrm{m}_{\mathrm{e}} \cdot \mathrm{k}_{\mathrm{m}} \cdot\left(\mathrm{k}_{\mathrm{i}}-\mathrm{k}_{\mathrm{a}}\right)}}
$$

where $\mathrm{n}$ is the gas density, $\Lambda$ - the mean diffusion length which depends on the reactor geometry and the wall sticking coefficient [14], $\mu_{\mathrm{i}}$ and $\mu_{\mathrm{e}}$ - the ion and electron mobilities, $\mathrm{m}_{\mathrm{e}}$ - the electron mass and $\mathrm{k}_{\mathrm{m}}, \mathrm{k}_{\mathrm{i}}$ 
and $\mathrm{k}_{\mathrm{a}}$ - the rate constants of momentum transfer, ionisation and electron attachment, respectively. The rate constants were calculated as:

$$
k=\int\left(\frac{2 E_{e}}{m_{e}}\right)^{1 / 2} \cdot \sigma\left(E_{e}\right) \cdot f\left(E_{e}\right) d E_{e}(2)
$$

where $E_{e}$ is the electron energy, $m_{e}$ the electron mass, $\sigma\left(E_{e}\right)$ the electron impact cross section and $f\left(E_{e}\right)$ the electron energy distribution function. A Maxwellian electron energy distribution was assumed.

Similar to [15] for given pressure, r.f. voltage, frequency, a self bias voltage of $U_{D C} \approx 0.587 U_{\mathrm{tf}}$, reactor geometry and wall sticking coefficient of gas species the rms current density, r.f. power, ion current density to the electrodes and the fractions of power dissipation in the discharge bulk, by "wave-riding" electrons at the sheath/plasma boundary and in the sheaths were calculated.

Contrary to [15], we assumed a mobility limited sheath of a thickness of:

$$
\mathrm{d}_{\mathrm{S}}=\sqrt[3]{\frac{9 \cdot \varepsilon_{0} \cdot \mu_{\mathrm{i}} \cdot \mathrm{U}_{\mathrm{s}}^{2}}{8 \cdot \mathrm{J}_{+}}}
$$

where $U_{S}$ is the sheath voltage and $J_{+}$the ion current to the electrodes, instead of a collisionless one, and calculated the power dissipation through electron collisions as:

$$
\mathbf{P}_{\text {coll }}=\mathrm{n}_{\mathrm{c}} \cdot \frac{\partial \mathrm{W}_{\text {coll }}}{\partial} \cdot\left(\mathrm{d}-2 \mathrm{~d}_{\mathrm{s}}\right)
$$

where $n_{e}$ is the electron density, $d$ the electrode gap and $\partial W_{\text {coll }} / \partial t$ are the compiled from literature power losses by elastic and inelastic collisions.

The one-dimensional diffusion equation of each radical specie is described as:

$$
-D \cdot \frac{\partial^{2} n}{\partial x^{2}}+k \cdot n_{S i H_{4}} \cdot n=F_{01} \cdot \delta\left(x-d_{s}\right)+F_{02}\left(x-d+d_{s}\right)(5)
$$

where $\mathrm{D}$ is the diffusion coefficient, $\mathrm{n}(\mathrm{x})$ the radical density, $\mathrm{k}$ the radical-silane reaction rate constant taken from [16]. The two sources of radicals are approximated to be localized at a distance $d_{s}$ from each of the electrodes. The radical source intensities $F_{0}$ were fitted to experimental results taking into account the silane fragmentation pattern. We assumed that the sheath thickness approximately determines the distance between the substrate and the source of radicals by electron impact dissociation of $\mathrm{SiH}_{4}$ molecules. This sources represent the high-energy tail of the electron energy distribution function which is "pumped" at the peaks of the rf-cycle, a result of the oscillating sheath. During the anodic part of the r.f. cycle the plasma electrons move toward the electrode while the sheath contracts. During the following sheath expansion the remaining electrons in the region close to the electrode are swept back into the plasma by the high sheath field forming thus a beam-like component of the electron energy distribution function. Bulk electrons are created in the plasma mainly by ionization by the beam electrons, ionization by electrons gaining energy from the bulk electric field is less important. The plasma field is low and contributes mainly to low energy excitation such as vibrational one (fig. 3). Thus, in our model the electron energy distribution is represented by two components: a bulk electron swarm (mean electron energy 1 to $3 \mathrm{eV}$ ) dissipating power mainly by vibrational excitation and a nearly monoenergetic electron beam generated by "wave riding" electrons at the boundary of the oscillating sheath contributing mainly to dissociation and ionization (fig. 3). Consequently, the well known transition to a secondary electron emission sustained discharge $(\gamma$ regime) occurs when the beam electron energy exceeds the thresholds of dissociative ionization (11.9 to $14.7 \mathrm{eV})$.

In principle, it is also possible that many low-energy collisions of bulk electrons could vibrationally heat silane in the discharge, causing dissociation similar to low-energy photons [18]. A significant amount of vibrational excitation is expected from a comparison of CARS, LIF and OES signal distributions between the cathode and anode of a parallel plate deposition reactor [19] showing a lower CARS signal in the central plasma region associated with a decrease of the vibrational ground state density of $\mathrm{SiH}_{4}$ in accordance with our calculations of power deposition by the bulk electrons (fig. 3). However, significant gas heating would have to accompany vibrational heating, and that is not observed [20]. More 
sophisticated calculations led to a fraction of power deposited by vibrational excitation of more than 0,2 resulting in a fractional density of vibrationally excited silane of less than 0,05 [16].

The silane fragmentation pattern was estimated as shown on fig. 4 compiling data from [21-25].

Radical diffusion coefficients were calculated using a Lennard-Jones 6-12 potential as described in [26]. Lennard-Jones parameters for silane species were taken from [16]. The results are in good agreement with measured values for $\mathrm{Si}$ [27], $\mathrm{SiH}$ [24] and $\mathrm{SiH}_{3}$ [28].

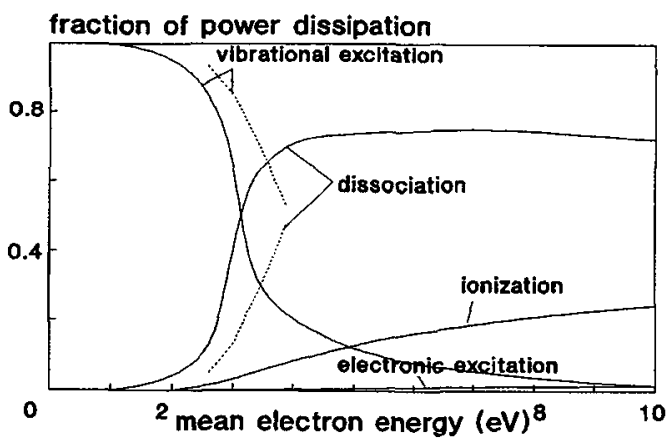

Figure 3: Partial contributions of vibrational excitation, dissociation, ionization and electronic excitation to the total power dissipation calculated using cross sections compiled in [16]. Calculation results from [17] (dashed lines) are plotted for comparison

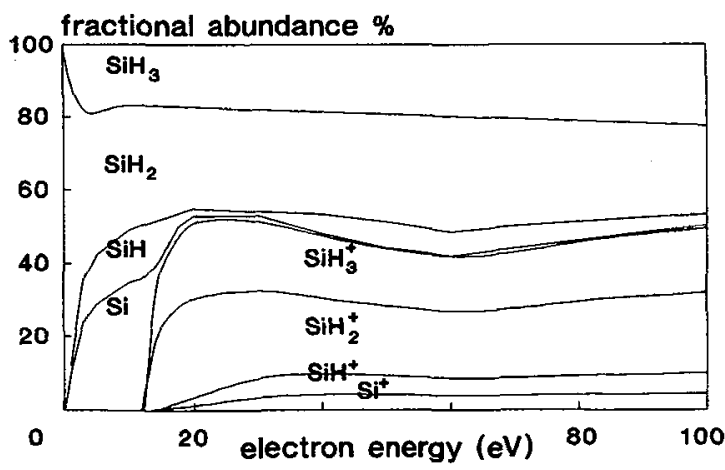

Figure 4: Silane fragmentation pattern in dependence on electron energy

Partially absorbing electrodes were assumed with a "linear extrapolation length" boundary condition [14]:

$$
n\left(x_{0}\right)=\frac{\partial\left(x_{0}\right)}{\partial x_{0}} \cdot \frac{2 \lambda}{3} \cdot \frac{(2-s)}{s}
$$

where $\lambda$ is the mean free path and $s$ the radical-surface sticking coefficient which was assumed to be 0,15 for $\mathrm{SiH}_{3}$ [29] and 1 for $\mathrm{SiH}_{2}, \mathrm{SiH}$ and $\mathrm{Si}$. Radical multiplication by hydrogen abstraction from silane was taken into account by the correction of the $\mathrm{SiH}_{3}$ flux with an empirical factor. 


\section{RESULTS AND DISCUSSION}

The r.f. power redistribution between plasma (collisional electron heating and heating by electron „wave riding ") and the sheaths (ion acceleration) is sensitive to the frequency. Since the sheath thickness decreases with increasing frequency (this increases ion directionality) and the velocity of sheath expansion increases, rising with frequency ionization rate, plasma density and ion current to the electrodes were calculated (fig. 5).

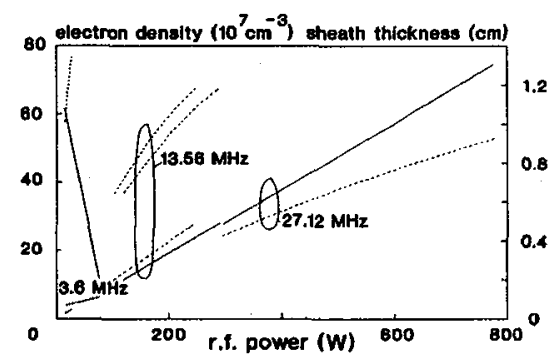

(a)

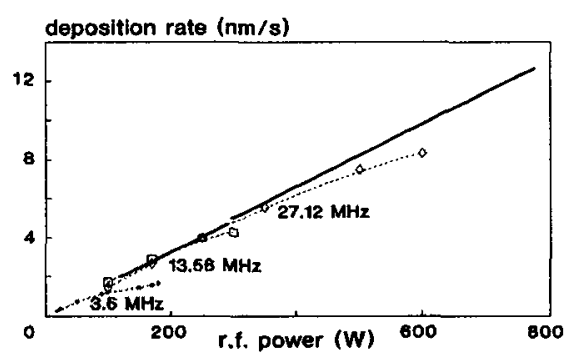

(b)

Figure 5: Calculated using PLASIM electron densities (solid lines) and sheath thicknesses (dashed lines) of the multipolemagnetic field enhanced coaxial glow discharge reactor [9] - a, and deposition rates - b, versus r.f. power. Curves on fig. 5a marked with asterisks were calculated using recently published cross sections [30], dashed lines on fig Sb show experimental data.

The application of a magnetic field normal to the electric field results in a redistribution of $r . f$. voltage between the sheath and the plasma. Electron confinement by the magnetic field reduces electron losses to the electrodes and the chamber wall thus increasing ionization efficiency. The result is a higher plasma density with lower sheath fields and a reduced sheath thickness. The mean energy of ions impacting the film surface decreases as in the case of frequency variation, but the ion current to the electrodes decreases too (fig. 2). Due to an effective confinement of the fast beam-like electrons higher radical source intensities and corresponding higher deposition rates were obtained.

The absence of low-energy excitation states of He greatly increases the calculated electron density for the helicon-type source, whereas only small changes of the sheath thickness result (fig. 6). Due to a different plasma chemistry, hydrogen bonding of the thus-deposited films differs completely from the others. Despite a pronounced microstructure determined from the ratio of the integral absorption strengths of the hydrogen related $1990 \mathrm{~cm}^{-1}$ (isolated $\mathrm{SiH}$ ) and $2070 \mathrm{~cm}^{-1}$ ( $\mathrm{SiH}$ on internal surfaces) peaks, densified (refractive index 3.0 , higher maximum values of $\varepsilon_{2}$ ) and thermal more stable, e.g. characterized by a more strongly hydrogen bonding, films were obtained having a TAUC-gap of 1.8 to $2.0 \mathrm{eV}$ which are promising candidates for higher band gap window layers of a-Si: $\mathrm{H}$ solar cells.
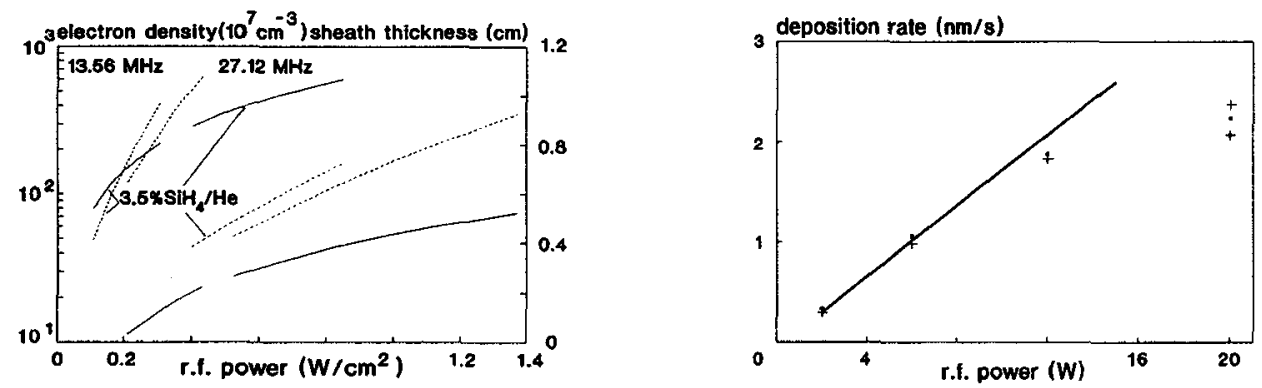

Figure 6: Calculated enhancement of the electron density by helium admixture -a, and deposition rates in the helicon-type source 
The less than linearly increase of the deposition rate with discharge power (figs. 5,6 ) is probably due to the reaction $\mathrm{SiH}_{3}+\mathrm{SiH}_{3}->\mathrm{Si}_{2} \mathrm{H}_{6} *$ whose rate scales as the square of the silane dissociation rate [16] and which was neglected by the calculations.

The energy flux to the substrate was determined from the ion current to the substrate electrode taking into account charge exchange collisions, and from the energy dissipation by vibrationally excited molecules. This energy flux to the substrate influences the apparent deposition temperature and thus indirectly influences the adatom mobility. Additionally, particle bombardment promotes the reaction heat. On the other side, chemical species react with the surface to create volatile products which desorb from the surface and are pumped from the reactor. Therefore, we assume that heats of surface reactions are nearly compensated by heat losses by vaporisation of the products from the surface. Radiative heat transfer is assumed to be negligible. Calculation results are illustrated on fig. 7a. Beyond the energy fluxes due to ion current to the substrate and due to deexcitation of molecules and radicals, the ion/neutral energy flux ratio was determined. Without a magnetic field there is a maximum of the energy flux ratio at about $60 \mathrm{MHz}$ (fig. 7b). By applying a magnetic field this maximum shifts to somewhat lower frequencies and lowers in value. Even at high ion/neutral flux ratios, high-rate a-Si:H films with a hydrogen content of less than 10 at $\%$ which are stable against illumination were deposited.

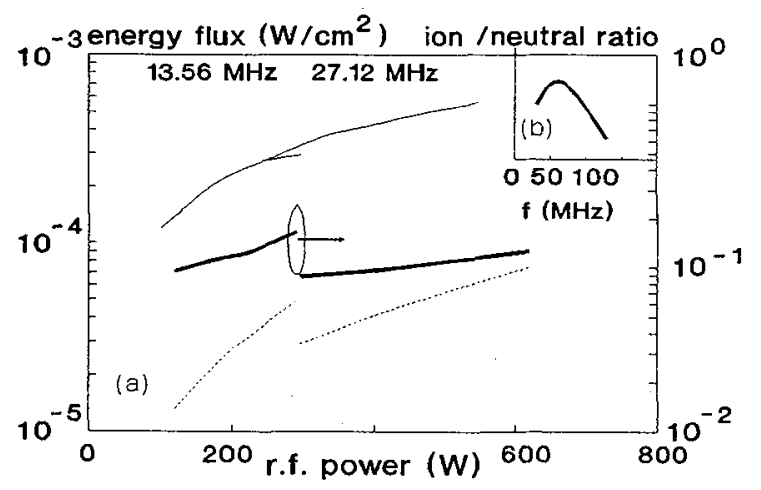

Figure 7: Energy fluxes to the substrate due to impact of excited neutral species (solid lines) and ion bombardment (dashed lines), ion/neutral energy flux ratio versus r.f. power for the magnetic field enhanced deposition reactor (a) and versus frequency for the VHF-reactor (b)

In conclusion, we demonstrate that by frequency and magnetic field variation stable against illumination a-Si:H films can be deposited at high rates of up to $8 \mathrm{~nm} / \mathrm{s}$. Both, frequency and magnetic field serve as parameters for optimisation of the energy flux to the substrate while the magnetic field enables us to perform high-rate deposition at lower r.f. voltages and at lower pressures avoiding thus dust formation due to plasma polymerisation.

\section{Acknowledgements}

This work was supported by the German Ministry of Research and Technology under contract number 0329563A.

[1] Mahan A.H., Carapella J., Nelson B.P., Crandall R.S. and Balberg I., J. Appl. Phys, 69 (1991) 67286730

[2] Papadopulos P., Scholz A., Bauer S., Schröder B. and Oechsner H., J. Noncryst. Solids $164 \& 166$ (1993) 87-90

[3] Jang J., Kim T.G., Kim S.Ch., Jun J.M. and Park K.Ch., Appl. Phys. Lett. 60 (1992) 2880-2882 
[4] Ganguly G. and Matsuda A., Mat. Res. Symp. Proc. 258 (1992) 39-44

[5] Vanecek M., Nelson B.P., Mahan A.H. and Crandall R.S., J. Noncryst. Solids 137\&138 (1991) 191194

[6] Das D., Shirai H., Hanna J. and Shimizu I., Jpn. J. Appl. Phys. B 30 (1991) L239-L242

[7] Shirai H., Hanna J. and Shimizu I., Jpn. J. Appl. Phys.B 30 (1991) L881-L884

[8] Suchaneck G., Alhallani B., Steinke O., Wirbeleit F. and Schade K., „High rate deposition of device quality a-Si:H“, 11th Int. Symp. Plasma Chem., Loughborough 22-27 August 1993, vol.3, J.E. Harry Ed. (Loughborough University of Technology, 1993) pp.787-792

[9] Röhlecke S., Tews R., Kottwitz A. and Schade K., „High-Rate PECVD of a-Si alloys on large areas“, Fourth Int. Conf. Plasma Surface Engineering, Garmisch-Partenkirchen 19-23 September 1994, (Deutsche Gesellschaft für Galvano- und Oberflächentechnik e.V., Düsseldorf, 1994) p.49

[10] Suchaneck G. and Schade K., ,a-Si:H deposition rate limits due to plasma polymerization in $\gamma$-regime low pressure if-discharges“, XXI. Int. Conf. Phenomena in Ionized Gases, Bochum 19-24 September 1993, vol III, G. Ecker, U. Arendt and J. Böseler Eds. (Arbeitsgemeinschaft Plasmaphysik, Bochum, 1993) pp.478-479

[11] Stephan U., Kuske J. and Schade K., Mat. Res. Symp. Proc. 336 (1994) 79-84

[12] Maley N. and Lannin J.S., Phys. Rev. B 36 (1987) 1146-1152

[13] Laudahn H. and Suchaneck G., 1992 (unpublished)

[14] Chantry P.J., J. Appl. Phys. 62 (1987) 1141-1148

[15] Misium G.R., Lichtenberg A.J. and Liebermann M.A., J. Vac. Sci. Technol. A 7 (1989) 1007-1013

[16] Kushner M.J., J. Appl. Phys. 63 (1988) 2532-2551

[17] Garscadden A., Duke G.L. and Bailey W.F., Appl. Phys. Lett. 43 (1983) 1012-1014

[18] Deutsch T.F., J. Chem. Phys. 70 (1979) 1187-1192

[19] Hata N. and Tanaka K., J. Noncryst. Solids $77 \& 78$ (1985) 777-780

[20] Hata N., Matsuda A. and Tanaka K., J. Appl. Phys. 59 (1986) 1872-1874

[21] Perrin J., Schmitt J.P.M., de Rosny G., Drevillon B., Huc J. and Lloret A., Chem. Phys. 73 (1982) 383-394

[22] Longeway P.A. and Lampe F.W., J. Am. Chem. Soc. 103 (1981) 6813-6818

[23] Turban G., Catherine Y. and Grolleau B., Plasma Chem. Plasma Process. 2 (1982) 61-80

[24] Schmitt J.P.M., Gressier P., Krishnan M., de Rosny G. and Perrin J., Chem. Phys. 84 (1984) 281-293

[25] Chatham H., Hils D., Robertson R. and Gallagher A., J. Chem. Phys. 81 (1984) 1770-1777

[26] Hirschfelder J.O., Curtiss C.F. and Bird B.R., Molecular theory of Gases and Liquids (Wiley, New York, 1954) pp.528-541

[27] Tachibana K., Tadokoro H., Harima H. and Urano Y., J. Phys. D 15 (1982) 177-184

[28] Itabashi N., Kato K., Nishiwaki N., Goto T., Yamada Ch. and Hirota E., Jpn. J. Appl. Phys. 28 (1989)

[29] Perrin J. and Broekhuizen T., Appl. Phys. Lett. 50 (1987) 433-435

[30] Nagpal R. and Garscadden A., J. Appl. Phys. 75 (1994) 703-709 